\title{
The Construction and Demonization of the Lazybones
}

\author{
Mikael Ottosson, Calle Rosengren
}

\begin{abstract}
I know that many ward managers sometimes feel frustration when people look into their office and say 'All right, there she is sitting at her computer again. Wonder what she's doing? Is she on the Internet or what?' (Hospital ward manager quoted in Rosengren \& Ottosson 2007:162)
\end{abstract}

\section{Introduction}

What constitutes work is not always clearly defined and what may be regarded as diligent work performance in some contexts may be viewed as idleness and passivity in others. Further, the societal norms that regulate our perception of work are temporally, spatially and socially unstable; an ambiguity that, in comparison to previous epochs, probably has increased as people's movements between various social, cultural and geographical contexts have increased. Within this motion, we exist and are influenced by various work ethics. The ward manager, interviewed at a Swedish emergency ward, suspects that the staff believe she spends work time surfing the Internet, so called cyber-loafing or cyber-slacking. She worries that they may feel she lacks work ethics or, even worse, that she is lazy. We probably all recognize the ward manager's feeling of frustration.

The present article addresses the building of norms that govern and regulate work and working life. We argue that it is necessary to view the individual work place and the organization's norms in a broader context, and to see them as part of a societal system of norms. This article focuses the linguistic metaphors and symbolic actions that are at once a manifestation of, are active in the creation of, and a vehicle for work norms. We subscribe to a discourse analytical approach and argue that our linguistic expressions correspond to our thoughts and social practices and thereby govern how we understand and categorize our surrounding world (Fairclough 1992; Lakoff \& Johnson 2003; Larsson 2012). In other words, our language does not only inform our thoughts but also which thoughts are possible to think and, as a consequence, which actions are possible to carry out. Simultaneously, linguistic expressions are context-bound and tied to specific situations. We will, therefore, take our starting point in the argument that our way of relating to work and work time fetches its sustenance from contemporary norms and that it is possible to observe the same system of norms active at different system levels. The ward manager's experience, therefore, is based in the same norm system that allows an unemployed person to feel "useless."

It should also be noted that although the article addresses a general problem, the text is written from a Swedish perspective. Finally, we use empirical examples retrieved from the Swedish election in 2010 which highlight active attempts to manipulate and reinforce certain norms.

\section{Work}

In the article "Time and the Negotiation of Work-Family Boundaries" Julia Brannen (2005) reflects on the 
length of work time in relation to the individual's possibilities and freedom to make her own decisions:

Paradoxically, it seems that the more autonomy employees are given over organizing their time in work seems to mean that they are spending longer and longer at work or working. (Brannen 2005:115)

The question Brannen poses concerns why we tend to work longer working hours, bring our work home with us and read our email at home, while our opportunities for autonomy and self determination have increased. The explanation is probably multifaceted; however, our focus of interest lies primarily in those norms that support these actions.

When we observe working life in Western society, it becomes clear that not only is the work itself of key importance but so, too, are our perceptions of it. Issues such as work organization, work time and work environment are difficult to grasp unless one also observes the cultural and normative content of the work. This becomes apparent not least in the fact that historically we have spent much time and effort reflecting on our and others' labor. Aside from working, we have also created theological and political systems to manage work and the distribution of its fruits. This relationship is, perhaps, not surprising given that we, in various ways, have been dependent on work. For many, the threat of destitution has been a driving force. People have diligently invested time and their bodies in theirs' or others' agriculture, factories, workshops and households to put food on the table. For others, work has been an interesting experience while living off and exploiting others' labor (Negrey 2012).

However, as several researchers have noted, this central position enduringly occupied by work is peculiar. Despite the fact that industrial society during, in particular, the late 1900s and early 2000s resulted in a dramatic increase in productivity, we are also expected to work more and longer hours. This does not merely relate to expectations despite the need for labor never having been as low, we work all the more (Paulsen 2013; Rifkin 2004; Schön 2012). Furthermore, it is also clear that the boundaries of work are dissipating in the wake of mobile communication solutions and social network services. Following in the trail of new technology and the digitalization of society, the previously, clearly defined boundary between work and privacy is weakening (Allvin 2011; Berkowsky 2013; Bittman et al. 2009). Paulsen (2013) argues that as productivity increases, work tends to expand and remain so throughout life, in practice. When more time becomes potential work time and more rooms becomes potential work spaces, we become increasingly exposed to work norms which, it may be reasonably assumed, also influence how work time is perceived at the individual level. This could explain Brannen's (2005) conclusion that we tend to work more as our autonomy increases. This can also be linked to Madeleine Bunting's (2005) extended and pertinent book title, Willing Slaves: How the Overwork Culture is Ruling Our Lives. However, this is not to say that this image of the central role of work is undisputed. Coincidentally, as work has come into the scope of both society's and the individual's focus, we have also attempted to delimit the extent of work. This has occurred in a political arena in the form of legislation and agreements, but there has also been a general perception that there is a need for a better balance between work and leisure. In one survey, for example, a majority of Sweden's population responded that they would prefer reduced work time to increased wages and consumption (Anxo 2009; Sanne 2007). Historically, increased productivity has been used to reduce work time, thereby increasing society's temporal welfare (Mulgan 2005). The first legislated work time restriction in Sweden can be traced back to 1920 (Ottosson \& Rosengren 2007) and a gradual decline in the number of worked hours can thereafter be seen during the remaining part of the twentieth century and up until 1973, when the 40-hour work week was fully implemented (Anxo 2009).

At the same time, the situation is complicated by the fact that work is not merely increasing in extent and invading leisure time but that leisure time all the more frequently leeks into work time. As the former, strict division between work and leisure grows lax (Allvin et al. 2011), in part due to digital technology (Berkowsky 2013), "empty labor" emerges in which we, during work hours, for instance listen to music, attend to private correspondence, and follow Internet auctions (Paulsen 2013). Research points out in part an increased boundlessness, in part a positive relationship between ICT, and both "negative home-work spillover" as well as "negative work-home spillover" (Berkowsky 2013).

\section{From Welfare to Work}

The work time paradox is also articulated in the explicitly political sphere. We are expected to work more and longer hours. Despite the increase in productivity, political successes today are measured by the number of 
jobs created and hours worked. This, of course, relates to the need to achieve a politically acceptable distribution of welfare; it relates to maintaining the funding of the state and public sector via payroll taxes: it relates to the management of demographic changes, but it also relates to societal work norms and, in the final analysis, a view of humanity (Paulsen 2013).

In political terms, the concepts of workfare and welfare are commonly used to express the two political, rhetorical systems that govern welfare and labor market policy. In short, workfare (work for your welfare) can be expressed as being based in the distribution of resources depending on the individual's work performance or work ethic, while welfare takes its starting point in that the state or society has a responsibility to ensure that the individual, irrespective of any participation in labor market policy programs, has a reasonable standard of living (Kildal 2000). Both political economic systems are, of course, more complex, however. For example, we can observe large institutional as well as cultural differences between various countries. What we denote as welfare usually also includes demands for specific activities. Within the literature, however, it is usually argued that welfare as a system differs significantly by being based in rights and possibilities, while workfare as a system is based in duty and sanctions to a greater extent (Kildal 2000). Central to the workfare perspective is the argument that too generous, undemanding and tolerant an attitude towards non-working individuals leads to passivity and counteracts personal responsibility. Workfare proponents further argue that an all too generous policy ultimately risks contributing to the buildup of a dependency culture and permanent social exclusion (Martin 2004).

Sonia Martin (2004) argues that the rise of workfare within social and labor market policy should be seen against a backdrop of the neo-liberal ideological hegemony of the 1990s, which has led to undermining the state's responsibility for the citizens' social welfare and been replaced by an increasing focus on the individual's idleness, as the explanation for economic inequalities. She argues that this has led to a displacement of the responsibility for poor social conditions from the state to individuals. Some researchers, for example David Byrne (2005), point out that within the neoliberal groove of thought, there are not only moralizing aspects but also notions of hereditary and racially contingent cultures of poverty. This naturally manifests itself differently in various countries, but the common denominator appears to be that characteristics that express otherness, for example, immigrants, the homeless, the young, blacks, welfare dependents, drug addicts, criminals and the unemployed are increasingly used to label individuals in the socially excluded "subclass" (cf. Byrne 2005; Marks 1991; Martin 2004).

According to the neoliberally influenced workfare ideology, unemployment and various other social problems are largely caused by the unwillingness of the unemployed to accept low wage employment (see, f. ex. Mead 1989). One consequence of this is that social and labor market policy thereby is directed towards creating incitements for the unemployed to accept such work. The path struck upon, therefore, is one that decreases access to, and lowers, benefits within the welfare and social security systems. Similarly to, for example, Byrne (2005), we argue that a key part of this policy has been to create a new work ethic by shaming and demonizing the unemployed.

\section{Work Norms}

The previously cited ward manager expresses how her work at the computer is reconstructed into an idle, disloyal and immoral action. Reminiscent of "the gaze of the other" (Sartre 1992), by being carried out without any transparency at the computer, work becomes non-work. Work appears here not as a given but as being dependent on the meaning it receives within its social context. In other words, to understand the situation, it becomes necessary to observe the norms and values that circumvent work and livelihood. These are key since they are crucial to the regulatory mechanisms within the individual's relationship to his work.

Norms are seen here as regulatory mechanisms in relation to explicit contracts of action such as, for example, directions for how and where to carry out work, specified work hours for when it is to be carried out or socially formulated expectancies of behavior. It is important to point out that at the core of the character of the norms that "regulate" our work performance lies a power structure in which various actors seek the privilege to interpret which norms are applicable and how they are to be understood. Several researchers also point out that the individual lives in parallel norm systems, systems which fetch nourishment from different societal contexts and situations (Rosengren 2009). Taking our point of departure in Hydén and Svensson (2008), we argue that norms essentially have three attributes which conclusively define the concept of norms. Norms are (a) guidelines for action (imperatives) which express a normative (ought) dimension; they are (b) socially reproducible and reproduced, and finally (c) they 
constitute the individual's perception of the social expectations of their behavior. At the same time, norms are unstable; our view of what is morally right changes over time. Work norms are not only recreated but also created and, thus, the question becomes how this occurs. Which actors are active and how is this influence manifested? Since our social system is neither equal nor egalitarian, it is unlikely that "norm production" would be either.

Below, we discuss this process from the standpoint of "diligence." One of the ways in which diligence materializes and becomes a guideline for action in contemporary Western working life, we argue, is in the willingness and readiness for long work hours. The question thereby concerns how this guideline for action is manifested and how it is produced and reproduced.

\section{Norms and Power}

Even if norm systems are constructed with the assistance of the use of language and actions within interpersonal interaction, the ability and capacity to influence and alter is not equally distributed. Different actors have access to different resources and from that perspective, it could be said that some actors wield more power over language and the development and construction of the norm system than do others. Organizations in working life, such as trade unions and employer's organizations, political parties and media companies, have other opportunities to communicate meaning-making guidelines for action that lie beyond the average citizen in the form of physical actions, images or text that inform on "what is possible" and what is "deviant." Power, with regards to norms, therefore concerns the possibility to "set the agenda" in that certain lines of thought become dominant (Lukes 2008). This exercise of power is expressed at various system levels. Previously, we discussed the ward manager's frustration (the individual level) and the formulation of and argumentation for the various welfare and/or labor market policy systems, i.e., welfare and workfare (social level). A corresponding process can be seen when corporations and organizations (organizational level), through management, attempt to influence the employees behavior and norms (e.g., Alvesson \& Wilmott 2002).

With regards to work time norms, it can be noted that both the way in which working time is organized and its symbolic expressions have changed. The factory whistles no longer sound, working schedules are becoming increasingly individualized and, according to Julia Brannen (2005), the outer control over working hours has been replaced by an inner control. In connection with this turn in the motivation to work, Brödner and Forslin (2002) use the concept "self-managed intensity". Using Norbert Elias' terms, this shift from an outer control to an inner control could be seen as part of a greater transformation process that Western civilization has been undergoing during modern times.

[...] we see clearly how the compulsion arising directly from the threat of weapons and physical force has gradually diminished, and how those forms of dependency, which lead to the regulation of the affects in the form of self-control, have gradually increased. (Elias 2000:157)

Meanwhile, as people in modern society have come to increase their control over their emotions, control over their work has been internalized - a process that must be seen as highly profitable for capitalists, as it has partly rendered supervision of the worker obsolete.

In order to comprehend why people, under certain circumstances, tend to work long hours in the absence of external restrictions, we consider other forms of control than that which takes form in external force: a more subtle form of control aimed at the employee's soul (Wilmott 1993). This form of control - the management of emotions - can also be viewed in Elias' extended context, which comprises the whole of society:

In a number of societies there are attempts to establish a social regulation and management of the emotions far stronger and more conscious than the standard prevalent hitherto, a pattern of moulding that imposes renunciations and transformation of drives in individuals with vast consequences for human life which are scarcely foreseeable as yet (Elias 2000:158)

From this point of view, a norm system is something that can be manipulated to achieve certain goals - rendering explicit regulations and direct surveillance obsolete. Hence, working life development could be seen as a shift from external and visible constraint to internal and invisible constraint, the latter constraint being administrated by the individuals themselves. In describing this process, Michel Foucault expressed that " [...] it is this inversion of visibility in the functioning of the disciplines that was to assure the exercise of power even in its lowest manifestations. We are 
entering the age of the infinite examination and of compulsory objectification". (Foucault 1995:189)

Economists Mats Alvesson and Hugh Willmott (2002) argue that companies manipulate corporate culture such that long working hours come to symbolize commitment and loyalty towards not just the company, but also towards colleagues. This manipulation can take the form of appealing to certain values or group affiliations. In a similar way, Sara Rutherford points to a strong masculinity ideal in her study on "the long hours culture" among British whitecollar workers. In the following quotation from one of her respondents, the masculine culture is made explicit:

[...] there was an element of macho competition over the number of hours worked. 'We had to do a presentation with only one week's notice recently and one chap worked 115 hours that week.' Said a senior director, with a certain amount of pride in his voice. (Rutherford 2001:273)

Besides the obvious reference to a not only masculine, but even macho culture, the quotation also contains a clue to how this kind of culture grows - namely through moralizing tales. Moreover, it also highlights the competitive aspects of long working hours. This is also evident in the following quotation: "We unofficially kept a league table of the people who worked the longest. The group that won were here until four in the morning." (Rutherford 2001:266).

\section{Long Working Hours as a Means to Constitute Belonging}

A norm system, however, is not a one-way street. It works in both directions in that it is constituted by human interaction, but at the same time is a precondition for any form of interaction. Here, belonging is seen as expressed - through various acts and symbols - in relation to norms and values. Thus, working hours become a way of constructing belonging and identity. If a voluntarily long workday symbolizes devotion to, responsibility for and fulfilment of one's duty towards the organization, then working time becomes a marker of personal identity. The individual describes him- or herself as desirable through fulfilment of the norms and expectations he or she identifies as embedded in the organization (Rosengren 2009).

If working hours are regarded as part of an identity-creating activity, readiness and willingness to work long hours could be seen as a way for the individual to mark his or her class. It is the dependent workers who follow detailed schedules and who arrive at and leave the workplace at the same time every day. In contrast to common workers, directors and white-collar workers are "free" to work long and irregular hours. In line with Sara Rutherford, Evitar Zerubavel argues for an interpretation based on the assumption that long working hours are a way of marking one's status.

It should be noted that, given the markedly distinct temporal profile of the professional commitments associated with high social status, high-ranking officials very often arrive at work "early" and leave "late" for the purely symbolic purpose of displaying their high status! (Zerubavel 1985:153)

According to Zerubavel, a pattern of behaviour characterized by early arrivals to and late departures from work symbolizes a person's social status as (seemingly) being devoted and loyal to the company and its goals.

In the form industrial society has been shaped into during the 1800s and 1900s, work time and capital have been a critical point of conflict; a conflict that has been waged at various levels. From instructions and the formulation of work regulations at individual work places to a more comprehensive struggle for how the citizen should dispose of his time in order to best serve society or the nation. The individual's time expenditure is thereby linked to moral perceptions of how the good citizen ought to behave. The perception of long work hours as necessary for society's wellbeing is therefore a historical continuum. In industrial-capitalist society, a work ideology was prevalent which prescribed that work was a "good, human activity" (Paulsen 2013). Work time has been portrayed as a national resource which, in extension, entails that the individual's work time has been formulated according to a near utilitarian calculation based in the maximization of the good of the many. In other words, it is not up to the individual to deal with work time, but rather, it becomes a national matter. This aligns well with the type of mutual dependency that Durkheim denoted as organic solidarity.

At this point, we can conclude that long work hours are rhetorically linked to good morals and taking both social and national responsibility. To work hard and long becomes, in this way, a positively charged, meaning-making activity. 


\section{The Construction and Demonization of the Lazy Bones}

We return here to our starting point in the introductory ward manager's quote. She feared being viewed as not merely a cyber slacker but also lazy and unproductive. A person who surfs the Internet privately while subordinates and colleagues work diligently. If there is one thing that is not socially acceptable, it is to be unproductive while others toil. We need only light heartedly consider Jerome K. Jerome when he writes, in Three Men in a Boat: "I like work: it fascinates me. I can sit and look at it for hours" (Jerome 1998). Our perception of what is morally right forbids us to relate to this statement at face value and, thus, it becomes good comedy. Jerome can, however, help us to illuminate work norms (Jerome 1889:244).

A deviant behavior only becomes visible and meaningful in relation to the norm system that the behavior violates and, for example, Hacking (2000) argues that the norm violation also constitutes a part of an interactive process which contributes to the construction of the individual's image of self as well as of others (see also Becker 1997). The opposite of diligence, or its binary opposite, can be said to be laziness. Above, we discussed whether the culture of diligence in contemporary society has a manifest guideline for action inherent in its willingness and readiness to work hard and long hours. We also argued that norms and guidelines for action are continuously reproduced. One way to approach this reproduction might be to observe the opposite of normatively correct work: non-work and the non-worker. Within political rhetoric based in workfare, as several researchers have noted, unemployment is linked to passivity and welfare dependency (f. ex. Byrne 2005; Marks 1991; Martin 2004). The question is whether it is possible to see a parallel with regards to the length of work time or rather, in this case, the unwillingness to work long hours and whether work time reduction, in political and medial rhetoric, is equated with passivity, rest or idleness? If that is the case, the advocate for reduced work time should be equated to a passive lazy bones. Above, we established that work in contemporary society is a normative, morally inclusive concept, and, thus, the question is what lies beyond the norm, that which is not, what it is that is deviant from the expected behavior. Provided that work is the norm, the individual who does not work, the marginalized lazy bones, stands out from the crowd and becomes more visible.

One of these demons of human creation that has always pursued us is the Lazy Bones, the one who does not work and do what is right, who wastes God's, their own or a potential employer's time through their lack of productivity or carelessness (see, f. ex. Ottosson \& Rosengren 2007). This is due to a lack of sufficient willingness to (wage-) work; they might even be suspected of being pathologically unwilling to work and thus deemed unable to occupy their unregulated time with meaningful content and, as a result, singled out as dubious and failed existences (Ottosson \& Rosengren 2015).

We can determine that the image of the Lazy Bones has stalked us throughout history and has, in various circumstances, emerged in public debate (Paulsen 2013; Saint-Amand 2011). Depending on circumstance, various characters have been summoned. Alongside the warning example of the Lazy Bones, a threat looming in the near future unless we do something, we find other figures such as people on sick leave or unemployed, scrap metal thieves, hippies, bank robbers and prostitutes. As Byrne (2005), for example, demonstrates, an image has been depicted of a threatening subclass culture, a subclass culture that must be combated (see, f. ex. Mead 1989). This relates to upbringing, creating work incitements, but also to a cultural struggle that is articulated in military terms (cf. Fairclough 1992). Ronald Reagan, who was influenced by, for instance, Lawrence Mead, saw it as his social duty to resist as if waging war on those forces that would bring down society: "Only our deep moral values and strong institutions can hold back that jungle and restrain the darker impulses of human nature" (Ronald Reagan quoted in Marks, 1991, p. 450). Other, somewhat less dramatic metaphors than Reagan's war metaphors, are linked to negatively charged expressions. For example, work is usually linked both to physical and mental health, while the opposite, not to work, has been viewed as physically, mentally and morally debilitating. To work is denoted as something healthy and wholesome, while not to work is unhealthy (Paulsen 2013).

However, the connection between people's moral standards and their activity is not clear cut; rather, it depends on social factors such as class, gender, ethnicity and age. What is perceived as work and non-work respectively also varies over time. What work is or is not cannot be explained merely by its activity; rather, it is highly contingent to society and culture. That which is classed as idleness when conducted by a middle aged man is viewed as wholly acceptable when conducted by a child, for example. Actions that are seen as laziness when carried out by a worker have not only been seen as acceptable, but even natural and morally right when carried out by the nobility and the bourgeoisie. Workers and peasants have been placed in correction houses, while men and women from better circumstances have unperturbed indulged in horse riding or long walks. Both informal norms and formal legislation have made 
distinctions based in social circumstances. It is clear that this culture of work and diligence is not egalitarian, but that it has distinguished and distinguishes between people.

If work is the morally right thing to do (at least for the working class), then willingness to work, as mentioned above, ought reasonably to be a very good way of expressing social belonging and inclusion. Since time is limited, this willingness needs to simultaneously correspond with a willingness to delimit and decrease life outside the workplace - rest, leave and leisure. An argument based in the will to delimit work time necessarily becomes a norm violation and deviant behavior. The question, then, is how the image of leisure relates to the norm and the guideline for action embedded in "long work days"? Do we also find the off-work individual in the neoliberal jungle?

During the entire history of industrialization, there has been a political will to delimit or reduce work time to the benefit of increased leisure and rest. Even if the motives have shifted from the rights perspective to one of maintaining the system, work time has generally been reduced during the 1900s. As a political rhetorical figure, for example, the triptych 888 was used as a symbol for the right to equal shares of work, leisure and sleep (Ottosson \& Rosengren 2007). During the second half of the 1900s, not the least women's organizations, the environmental movement and an anti-capitalist youth movement formulated the six hour work day as a political demand (Ottosson \& Rosengren 2015). Reduced work time was then linked to concepts such as tenacity, a lesser environmental burden and personal development (Ottosson \& Rosengren 2015). Simultaneously, during the 1900s, counter images were brought forth (Ottosson \& Rosengren 2007; 2013; Paulsen 2013). The counter argument to reduced work time was often waged through moral arguments - for example, it was argued that people fare ill from too much leisure; that workers may lapse into staring at the TV, intemperance and immorality. Arguments based in the wellbeing of the nation have also consistently been raised. Since demands for shorter work hours initially emerged towards the end of the 1800s, it has been maintained that the nation's work force would not suffice. If the needs during the early 1900s were military ones, towards its end, they had become healthcare, education and welfare needs. Non-work was thereby not only formulated as non-productivity but also as consumption at the expense of the needy (Ottosson \& Rosengren 2007; 2013; Paulsen 2013).

Although work time reduction, in general, was a positively charged concept during the greater part of the 1900s, during the early 2000s it has been replaced by the concept of work strategy. Although this may seem a rather severe simplification, it could be said that work overtook the role of the positively charged concept from leisure. Rather than question how work time could be reduced, the starting point in political debate became how work time could be increased (Paulsen 2013). The concept of work strategy was linked ideologically, in the late 1900s, to workfare. Today, in line with this shift of perspective, debate on shorter work time is politically dead. We can state that there has been a rhetorical reversal and the question is, based in the arguments above, whether the "Lazy Bones" is a character that has thereby been deployed. Has whoever desires shorter work time been portrayed as an advocate of non-work, of non-productivity and, thus, of laziness? We argue that within a Swedish political context, this process can be linked to the Swedish Employers' Confederation's (SAF) political offensive of 1975 (Ottosson \& Rosengren 2015). In a previous study, we demonstrate that SAF consistently uses rhetoric that places great value in work and that work has consistently been pitted against passivity. Reduced work time was clearly linked to inactivity and thereby became an attack on society's and the individual's wellbeing. The principal character in SAF's rhetoric is the Lazy Bones, he who will not work and do the right thing, he who wastes time. Within this rhetoric, the Lazy Bones is represented as a degenerate and immoral character who consumes leisure (Ottosson \& Rosengren 2015).

Without in any way presuming to summarize the materials and conclusions of a generally broad scope, below we will present some examples from the Swedish election campaign in 2010. One component of this election campaign was the conservative and the liberal parties' counter arguments to one of the Green Party's (Miljöpartiet) standpoints - a general work time reduction. The conservative newspaper editorials depicted both graphically and textually an image of the Green Party leaders lying about in hammocks. The images, published repeatedly, share several common denominators which can all be traced to idleness.

In the hammock a person reclines restfully with a mobile phone or at best a book. The images link to traditional imagery of lazy and unproductive individuals idly stretched out on their kitchen sofa. This morally reprehensible imagery is often reinforced by the presence of someone else at work. To "lie on the kitchen sofa" is, perhaps, one of the most emphatic expressions of passivity and unwillingness to work in the Swedish language. A similar expression is, "to lie on the lazy side." Commonly, these images can be seen in popular culture, for example, in comic books, films and TV. Towards the end of the 1900s, perhaps tinged by Southern European influences, the Lazy Bones is portrayed with increasing frequency as lying in his hammock. The hammock and the kitchen sofa become, in other words, images or metaphors that are distinctly charged with a negative connotation of laziness. 
During the Swedish election in 2010, advocates of shorter work hours ended up depicted in this mode of idleness. If the graphic image is one of a hammock, the linguistic equivalent is the Spanish word for midday rest, siesta. For instance, member of parliament Tomas Tobé of the Moderate Party wrote in an article entitled "Sweden can't afford siesta politics” in the Sydsvenska Dagbladet (14 May 2010). In an opinion piece in the Västervikstidningen, “The Green Party's Siesta Politics", the editor illustrates the article with an image of a man reclining in a hammock (Västervikstidningen 1 August 2010). Previously, the same image had been used by liberal Sydsvenska Dagbladet (26 May 2010) when illustrating an opinion piece by Ulf Holm of the Green Party. Alongside the article, the editor has inserted - you guessed it - a man lying in a hammock. Beneath the hammock, we see a deceptive caption, "Work Politics?" Whenever ideas and proposals of reduced work time were illustrated during the spring and summer of 2010, siestas and hammocks were commonly employed as rhetorical devices. One further example of unhealthy hammock slouching is to be found in the liberal newspaper Expressen (31 March 2010) beneath the caption "The Lazy Bones" in which Green Party leader Maria Wetterstrand is portrayed. In this article, Expressen's editorial writer vigorously attacks the Green Party's politics within the sphere of working life. The text is illustrated with a photomontage in which Maria Wetterstrand has been framed in a passive and work-free condition. Naturally, she reclines in a hammock. She would appear to be quite content. Smiling, she lies back, reading what we can only assume is an enjoyable book. In these newspaper articles, the concept of reduced work time is clearly linked to negatively charged metaphors such as "lying on your back", "hammock" and "siesta." Both text and images interact and this combination expresses that which cannot be written (cf. Ottosson \& Rosengren 2013). The reader and observer is allowed to come to their own conclusion that Holm and Wetterstrand indeed are genuine Lazy Bones. Irrespective of whether the illustrative images have been purposely selected to reinforce a political message or not, the connection has been made and remains with the reader. The hammock-lounging Lazy Bones becomes a representative of that which is sick and parasitical in society.

By being placed in hammocks, both Green Party politicians Maria Wetterstrand and Ulf Holm become disloyal consumers of a commonly produced prosperity. Consuming resources while lying in a hammock is a serious offence, since it entails shirking from your social responsibility. The individual who is willing to work hard is a good and admirable person, while the person who would work less becomes a disloyal social parasite. With his talk of shorter work hours, the hammock-lounger breaks down our morals. The Lazy Bones eats his way into the fruits and consumes them from within. Reduced work time becomes thereby equated to increased inactivity and, similarly to the events in Reagan's jungle, a moral attack on the wellbeing of society.

Beyond the limits of work, we find not only non-work, but also laziness, mental ill-health, and vice. The conceptual polar pair of "nourishment - debilitation" coincides with "healthy - unhealthy." The work norm entails that the division between work and non-work not only becomes a question of individual livelihood and lifestyle opportunities but also that the division becomes a moral division. Therefore, in line with this, the advocate for reduced work time also becomes an advocate for increased depravity. Based in the same norm system, the ward manager experiences frustration at the fact that the staff doubt her work input. Since work at the computer is not considered real labor in this department, she too crosses the same normative line.

\section{Conclusion}

This article is primarily theoretical and the presented empirical data are limited. From a theoretical methodological standpoint, the article takes its starting point in a discourse analytical perspective in which we have studied how concepts are defined and given meaning by being equated with metaphors and images that clearly are normatively charged. In this article, we have attempted to link the individual's experience at her workplace with social and labor market policy.

The article is based in an individual's experience of not fulfilling expectations and, instead, is suspected of being a lazy and unproductive worker. It seems reasonable to assume that her suspicion is due to the fact that her work at the computer is not considered "real work." To understand this situation, we argue that it is necessary to observe the normative content of work. Certain activities in specific situations tend to be judged as work, while other activities tend to be judged as the polar opposite of work: non-work. This non-work and those who conduct it, the Lazy Bones, are perhaps most easily located within the rhetorical language employed by advocates for increased workfare elements in the welfare system, such as in social and labor market policy. We argue that the individual experience of 
insufficiency and the viewpoint that the unemployed are unwilling to work (and are therefore lazy) are based in the same norm system.

Norms constitute the key theoretical concepts in this article. We argue that norms are (a) guidelines for action (imperatives) which express a normative (ought) dimension; they are (b) socially reproducible and reproduced and finally, (c) they constitute the individual's perception of the social expectations of their behavior. Central to this is also the fact that norms regulate our work performance and are based in a power structure in which various actors seek the privilege to determine the validity of norms as well as their interpretation. Norms are constituted by human interaction, but are simultaneously a precondition for any form of interaction. In relation to norms, belonging is seen as expressed - through various acts and symbols. Thus, working hours become a means to construct belonging and identity. If a voluntarily long workday symbolizes devotion to, responsibility for and fulfilment of one's duty towards the organization, then working time becomes a marker of personal identity. The individual describes him- or herself as desirable through fulfilment of the norms and expectations he or she identifies as embedded in society.

This article leads towards a discussion on how the debate on reduced work time was conducted in the Swedish election in 2010. The newspaper materials we have presented clearly demonstrate that the image of the advocate for reduced work time is placed in a context that is similar to the depiction of the "non-worker", which is prevalent both in neoliberal workfare arguments as well as individual workplaces. We argue that the glue that binds the department manager's frustration, the rhetoric surrounding the welfare state, the willingness to work long hours and the rhetoric surrounding shorter work hours, consists in the norm system which regulates work at a societal level.

In this article, we have argued from the standpoint that this same norm system that makes the unemployed feel useless also creates positive value in working late nights. Our contribution, therefore, is (1) that we have highlighted the significance of work norms within the evolution towards a borderless working life; (2) that we have demonstrated that the norms that govern and regulate work are constructed at various levels of society: and finally (3) we have demonstrated how norms can be communicated and reproduced by linking concepts to positively or negatively charged concepts.

We argue that a key (meaning making) character in the construction of this norm system in various contexts is summoned forth in the demon of the "Lazy Bones." Having breathed life into this warning example, it now wanders the offices, beaches and cafes, reminding us of the elevated value of work. It follows, then, that we would prefer to keep the "Lazy Bones" at arm's length and by working long hours, depict ourselves to others as good citizens.

\section{References}

Alvesson, Mats. \& Willmott, Hugh. 2002. "Identity regulation as organizational control. Producing the appropriate individual", Journal of Management Studies. Volume 39, Issue 5, pages 619-644.

Allvin, Michael. 2011. Work without boundaries: psychological perspectives on the new working life. Oxford: Wiley-Blackwell.

Anxo Dominique. 2009. "Working time policy in Sweden". In JLPT Report no 7. Working time - in search of new research. Territories beyond flexibility debates.

Becker, Howard S. 1997. Outsiders: studies in the sociology of deviance. New York: Free Press.

Berkowsky Ronald. W. 2013. "When you just cannot get away: exploring the use of information and communication technologies in facilitating negative work/home spillover". Information, Communication \& Society 16 (4): 519-541.

Brannen, Julia. 2005. "Time and the Negotiation of Work-Family Boundaries", Time \& Society, 2005:14.
Brödner, Peter \& Forslin, Jan. 2002. "O tempora, O mores! Work intensity - why again an issue?". In Docherty, Peter; Forslin, Jan. \& Shani, Rami. (eds.). Creating Sustainable Work Systems, London: Taylor \& Francis.

Bunting, Madeleine. 2005. Willing slaves: how the overwork culture is ruling our lives. London: Harper Perennial

Byrne, David. 2005. Social Exclusion. Maidenhead: Open University Press.

Elias, Norbert. 2000. The civilizing process, Oxford: Blackwell.

Fairclough Norman. 1992. Discource and social change. Cambridge: Polity.

Foucault, Michel, Sheridan, Alan. 1995/1977. Discipline and Punish: The birth of the prison. New York: Vintage Books.

Hacking, Ian 1999. The social construction of what? Cambridge Mass.: Harvard Univ. Press. 
Hopbsbawm, Eric J. 1968. Labouring men - studies in the history of labour. London: Weidenfeld and Nicholson.

Hydén, Håkan \& Svensson, Måns. 2008. “The Concept of Norms in Sociology of Law”. Scandinavian Studies in Law. 2008:53.

Ivarsson, Lars. \& Larsson, Patrik. 2011 "Personal Internet Usage at Work: A Source of Recovery". Journal of Workplace Rights; Vol. 16.

Jerome, Jerome K. 1889. Three men in a boat (to say nothing of the dog). Bristol: J. W. Arrowsmith Quay Street.

Kildal, Nanna. 2001. Workfare Tendencies in Scandinavian Welfare Policies. Geneva: International Labour Office.

Lakoff George. \& Johnson Mark. 2003. Metaphores we live by. Chicago: University of Chicago press.

Larsson, Stefan. 2012. "Copy me happy: the methaporic expaansion of copyright in a digital society". Semiot law 2013.

Lukes, Steven. 2005. Power: a radical view. Basingstoke: Palgrave Macmillan.

Marks, Carole. 1991. "Source The Urban Underclass". Annual Review of Sociology Vol. 17: 445-466.

Martin, Sonia. 2004. "Reconceptualising Social Exclusion: A Critical Response to the Neoliberal Welfare Reform Agenda and the Underclass Thesis", Australian Journal of Social Issues vol 39:79-94

Mead, Lawrence. 1989. "The Logic of Workfare: The Underclass and Work Policy". Annals of the American Academy of Political \& Social Science. 501: 156-169.

Mulgan, Geoff. 2005. "The arrival of time politics". In Aldrich, Tim. E. (ed.) About time: speed, society, people and the environment. Sheffield: Greenleaf

Negrey, Cynthia. 2012. Work time: conflict, control, and change. Cambridge: Polity

Ottosson, Mikael \& Rosengren, Calle. 2007 “Among Keen Men and Pampered Ladies. The Eight-hour workday debate in Sweden”. In Kimber, Julie \& Love, Peter (eds.). The Time of Their Lives: the Eight Hour Day and Working Life.Sydney: Labor history.
Ottosson, Mikael \& Rosengren, Calle. 2015. "What the Hell is a High Standard? The Swedish Employers' Confederation and the Six-Hour Workday debate in the mid 1970s". (Accepted for publication 2015) Nordic Journal of Working Life Studies.

Paulsen, Roland.2013). Empty labor: subjectivity and idleness at work. Ph.D. dissertation Department of Sociology. Uppsala University.

Rifkin, Jeremy. 2004. The end of work: the decline of the global labor force and the dawn of the post-market era. New York: Jeremy P. Tarcher/Penguin.

Rosengren, Calle. 2009. On the symbolic side of working time (Arbetstidens symbolvärde: om historisk kontinuitet och förändring i synen på arbetstid samt normers inverkan påarbetstidens gestaltning). Ph.D. dissertation Department of Industrial Economics and Management. Royal Institute of Technology in Stockholm.

Rosengren, Calle \& Ottosson, Mikael. 2007. "From white dress to white collar. A historical perspective on the hospital ward administrator". In Aili Carola, Nilsson Lars-Erik, Svensson Lennart G. \& Denicolo Pam (eds.), In Tension Between Organization and Profession. Professionals in Nordic Public Service. Lund: Studentlitteratur.

Rutherford, Sara. 2001. "Are you going home already". Time and society 2001:10:273.

Saint-Amand, Pierre. 2011. The pursuit of laziness: an idle interpretation of the Enlightenment. Princeton, N.J.: Princeton University Press.

Sartre, Jean-Paul \& Barnes, Hazel Estella. 1992/1956. Being and nothingness: a phenomenological essay on ontology. New York: Washington Square Press.

Schön, Lennart. 2012. An economic history of modern Sweden. London: Routledge.

Wilmott, Hugh. 1993 "Strength is ignorance; Slavery is freedom. Managing culture in modern organizations". Journal of Management Studies 1993 (30)

Zerubavel, Evitar. 1985. Hidden rhythms. Schedules and calendars in social life. Berkeley: University of California Press. 